\title{
Wandering between adherence and transcendence---- A brief talk about Xu Hai's calligraphic art
}

\author{
Guohua ZUO \\ College of fine arts, Huanggang Normal University, Huanggang 438000,China
}

Keywords: calligraphic art, big-seal style, running \& cursive script

\begin{abstract}
Xu Hai is a calligrapher who is active in the present calligraphic community and has high attainments in calligraphy and seal cutting. He also has deeply studied seal character and cursive script. Among these, his works of big-seal style are primitive and crude and probabilistic, all of which have a big effect on his style of seal cutting. Besides, his running \& cursive script works have a romantic charm of the calligraphic style of "er-wang" and the characteristics of wild leisure. His works often have unique novelties. Moreover, the classic elegance of the traditional calligraphy and the styles and features of modern calligraphy coexist in the form composition, style of writing and ink style of his works.
\end{abstract}

\section{Introduction}

$\mathrm{Xu}$ Hai is an outstanding person who is active in present calligraphic community. He not only has deep research on traditional calligraphy art but also has great attainments and original viewpoints on Chinese paintings and seal cutting. Thus he is still in an outstanding status among contemporaries.

Xu Hai's exquisite calligraphic skills left me a deep impression. I remember that his exhibition of painting, calligraphy and seal was held grandly on July 5th, 2009 in Pinglong, Shandong Province. The exhibition was hosted and sponsored by the Publicity Department of the CPC Pingdu Municipal Committee, Shandong Province, undertaken by Qingdao Tianzhu Research Institute on Painting and Calligraphy, and co-hosted by Chinese Calligraphic Institute of Chinese Art Institute and College of Chinese Painting of Central Academy of Fine Arts. On the exhibition, more than 60 works are presented. From these works, it can be found that $\mathrm{Xu}$ Hai has profound traditional foundation and valuable initiative spirits, which are incisively and vividly expressed in the simple and unadorned big-seal style of Zhou and Qin, in the poise and charm of cursive handwriting of Wei and Jin dynasties, and even in the wild leisure of the running script of Ming and Qing Dynasties. After watching all these works, I was really amazed because he composed these works and got great achievements rightly a little over the age of 40s. He not only has profound skills in calligraphy attainments, also the seal cutting skill is as grand and magnificent and unique as his calligraphic skills. Most importantly and impressively, Xu Hai has a deeper research on mountains-and-waters paintings and shows special artistic style.

Being a youthful calligrapher, Xu Hai has gained great artistic achievements. His calligraphy works was awarded the national award in the Fifth National Calligraphy Seal Cutting Exhibition, first prize in The Sixth And Eighth National Young and Middle-aged National Calligraphy Seal Cutting Exhibition and the second prize in the Seventh National Young and middle-aged Calligraphy, Seal Cutting Exhibition and attended the first annual exhibition of Chinese Calligraphy. He also participated in the first four Seal Cutting Exhibitions and the first three Popular Calligraphic Style and Seal Style Exhibitions. Besides, he issued books such as, The Collection Of The National Young and Middle-aged Calligraphy Engraver---Xu Hai's Chapter and The Collection of Contemporary Famous Young and Middle-aged Calligraphers --Xu Hai's Chapter. Being a professional calligrapher, Xu Hai also gained achievement in mountains-and-waters paintingS, which made him get the Award of Excellence in the Tenth National Fine Arts Exhibition and got honorable mention in 2004 in The Exhibition of Excellent Chinese Painting of National Young 
Teachers of Art Academic Colleges. From all of his achievements, we can find that Xu Hai is a calligrapher who has comprehensive artistic accomplishments. He is also an accomplishment calligraphy engraver and painter. Among the contemporary youth calligraphers of present calligraphic community, the crowds like Xu Hai who has so great artistic achievements are really rare.

His works of big-seal style are mostly from bronze inscription, such as San Family Plate, Duke Mao Tripod. The style of writing combines calligraphic style of bamboo slips of Han Dynasty with running script together, among which simplicity and vividness coexist, momentum and delicacy coexist naturally with proper density and moistness. Xu Hai is one of the doctoral candidates of the Mentor Wang Yong. His creating directions are fine arts and the creation of Chinese calligraphy, painting and seal in China Art Research Institute, which also provides a wide platform for his study of Chinese traditional painting, calligraphy and seal cutting art. He knows clearly about the relationship among calligraphy, painting and seals, so he combines seal cutting with big-seal calligraphy. Also he connects the calligraphic style of mountains-and-waters paintings with calligraphy together because he is influenced by Huang Binhong and his tutor Wang Yong, which makes his lines of big-seal style show strong art expressive force. The works of Xu Hai convey us a feeling of confidence and pride, which is an innovation after absorbing and digesting traditional calligraphy based on profound traditional foundation, or is "defamiliarization" of traditional calligraphy after being familiar it. Therefore, his works have both profound traditional cultural deposits and strong period feel. His big-seal works exaggeratedly pay much attention to the tension of the lines, sometimes, he even shakes the lines to stress the lift and press of lines and highlight the reflection and echo of the first and last strokes, which shows "wide, primitive and wild" artistic style. However, these features may become affectation if they are paid little attention, however, Xu Hai could properly use "the law of nature" , just as Lao Zi said:” Man follows the earth ,the earth follows heaven, heaven follows Dao, and Dao follows nature ". [1] From this, it can be concluded that during the period of composing calligraphy works, one should obey the objective law of calligraphy creation, at the same time, he can properly stress the subjective expression to show the features of art making. All of these characteristics in his works of big-seal style can unconsciously influence his style of seal cutting which is primitive and crude, powerful and wayward.

Through appreciating Xu Hai's works of running script, we can find that he learn the structure and calligraphy from a wide fields, including, seal of Qin and Han, works of Song and Yuan, and various fields of Ming and Qing ranging from ritual vessels, mirror inscription, Han bamboo strips, words on Shu and gravestones. However, when we scan the whole style of his works, he has the romantic charm of “er-wang” and wild leisure of Ming and Qing. He has a deep understanding on Wang Duo's cursive script and is the successor of this. His works of cursive script extremely pay attention to the form constitution and correlation. His characters are of large-scale cooperation with precipitous structure and tension. In his style of writing, he stresses the comparison of hide and exposure, virtualization and actuality. In lines, he highlights the comparison between thick and thin, long and short, twisted and straight. In the structure, he pursues the contrast between big and small, upright and strange, controlling and releasing. In ink techniques, he stresses the combination of dense and light, dry and wet, withered and moist. In art of composition, he connects the techniques of expression together such as, sparse and thick, complete and scattered, violative and harmonious. Most of his works get the essence of Wang Juesi's calligraphy and borrow from tablets of Wei Dynasty and Zhuanli to form a novelty and classical artistic pattern. Moreover, his cursive script are presented in the form of the science of calligraphic copies elegantly and brightly with the calligraphic style of "er-wang". However, the structure is a little far away from "er-wang", which is related to his artistic concept. When he works as a teacher in Central Academy of Fine Arts, he always suggests the students to change the traditional calligraphy-modeling to "paint from life ". I think this is a good method for writers who have a rather good calligraphic foundation, and it will also lead the learners to the creation stage naturally from simple modeling. The idea "paint from life " mentioned here means that learners can facsimile differently with the original copies and they 
can either pay attention to "representing" or " expression”, "write or paint realistically" or "being abstract, " and "subjective" or "objective". Sometimes, even the exaggeration of character pattern and remoulding the linetype are available. Actually, no matter which part is paid much attention to, the language itself will not change. Therefore, the pencraft, structure and composition should be put into a large frame, including, aesthetic principles, artistic rule and aesthetic model. People usually think that people who have profound foundation are those who can write standard typeface of "er-wang" or Su, Huang, and Mi. Actually this kind of thoughts are unilateral. So when we talk about the traditional calligraphic art, we can not take a part for the whole. Wang Xizhi's and Wang Xianzhi's calligraphy and Su, Huang, and Mi's calligraphy are certainly excellent, but they only stand for a certain artistic school and style of ancient calligraphers, so they can not cover the whole calligraphic arts. Those calligraphers who can inherit the artistic spirits of Wang Duo, Zhang Ruitu, Deng Shiru, Zhao Zhiqian, Huang Daozhou and Kang Youwei are also calligraphers with profound traditional foundations. Of course, the works of Xu Hai are different from er-wang's and Su, Huang and Mi's calligraphy. Although he borrows Wang Youjun's style of writing, he has already digested er-wang's calligraphy in his works. Besides, his style of writing and structure are close to Wang Duo of Qing Dynasty. Moreover, his art of composition and ink style are also influenced by Wang Duo, from which we can find that Xu Hai is deeply in love with calligraphy of Ming and Qing Dynasties. His success also proved that under the present exhibiting model of modern calligraphy, how important the sense of artistic form and the tension of lines are! Perhaps this "wide, primitive, and graceful" style accords with the living tempo of fast-food style and the traditional er-wang's and $\mathrm{Su}, \mathrm{Mi}$, Huang's calligraphy are too popular to gradually disappear.

\section{Xu Hai has made brilliant achievements in calligraphy and painting.}

In recent years, his calligraphy works and paintings are more than seal cutting works. As he is a teacher of Central Academy of Fine Arts, he can not finish seal cutting works continuously. [2] As for his skills of seal cutting, some people think he ranks the first position in those fields that he is good at. Of course, different people have different opinions, so it is rather difficult to rank among those calligraphers who are at the same artist level and class. However, from another perspective, it is unnecessary and helpless to rank as art is not a scientific calculation and many things about it depend much on felling. However, feeling is various from person to person, so different people and collective will give various evaluation to the same works. As for Xu Hai's works, I love them very much. His seal cutting style is unadorned and antique, reckless and indulgent. It not only has the taste of primitive crudity style of big-seal style, it also has the freehand brushwork of cursive script. It is lively and vivid and naïve. Moreover, it is as rough as stone inscription study and as delicate as the study of calligraphy book history with its own inherits and origin for each character. The name of Half-step Zhai is a true reflection of his calligraphic art. It also shows that his art is wandering between inheritance and innovation, and adherence and transcendence. As for the traditional calligraphic art, he uses "Half-step" to express the deepness of his study. On the other hand, it shows that when he is inheriting the artist style of his tutor, he is searching for a new breakthrough and has the confidence to go ahead.

From the lectures given by $\mathrm{Xu} H a i$, we can find that he is unadorned and sincere but humorous teacher. Being the associate professor and master supervisor of Central Academy of Fine Arts, a famous institution of higher education, he is extremely excellent in the view of most people. Besides, he is awarded with many prizes in many competitions, which also earns him a good reputation in calligraphic community. It is really valuable for him, who is a contemporary youth calligrapher and an associate professor and is called the "specialized households of prizes" by his fans to act honestly and gently. It reminds us of considering him a hardworking and modest person through these phenomenon. The signature of his works is often "Daliang Xu Hai" , which shows that he has profound knowledge in traditional calligraphy and he can absorb and digest traditions and integrate with the present age. Therefore, because of these reasons, he can be admitted by the society and he can get praise from judging panel, other calligraphers and his fans. We can say that his achievements are greatly influenced by his tutor, Wang Yong, who is called "Qi Baishi of the 
contemporary era " as he has high attainments in many field such as, poetry, calligraphy, painting and seal cutting. Being an all-round artist, he always teaches his students the skills without reservation and $\mathrm{Xu}$ Hai is the artist palmer who can inherit his legacy and form his own style.

Xu Hai's works pursue tranquilization and the character pattern is changeable, steep, straight and amazing. The lines are drawn casually and have an excellent integration of thick and thin, clumsy and artful, powerful and graceful, ordinary and novelty. Also the characters are set reasonably in both perpendicular and horizontal and gives us a strong visual impact force. Besides, the works are full of new conceptions and the strong feel of the period with profound cultural accumulation. In a word, the calligraphic works of $\mathrm{Xu}$ Hai have the artist features of "wide, primitive, and graceful", which wins him an important position in the Contemporary Chinese calligraphic community.

\section{References}

[1] Cao Yang, Zhou Ruchang. The calligraphic research on aesthetic ideology [D] Henan University, 2013

[2]Gu Liting. Being innocent with some ambitions_- the summary of the seminar The Seal Book of Haitangfang [J]oriental art, 2012 